\title{
Mesopancreas_-new unknown land or a mirage?
}

\author{
Marek Olakowski ${ }^{1}[$ ]
}

Received: 19 October 2021 / Accepted: 24 October 2021 / Published online: 31 October 2021

(C) The Author(s), under exclusive licence to Springer-Verlag GmbH Germany, part of Springer Nature 2021

Pancreatic cancer is a highly fatal disease with a 5-year survival rate of approximately $10 \%$ in the USA, and it is becoming an increasingly common cause of cancer mortality [1].

However, many advances made over the past decade in the safety and efficacy of surgery have resulted in 5-year survival approaching $30 \%$ after resection and adjuvant chemotherapy [2].

In many articles, a positive resection margin is a strong predictor of long-term survival after pancreatic cancer resection [3].

Recently, among pancreatologists there has been an increased interest in the space that is located on the dorsal side of the pancreas. It has been termed the mesopancreas. The name was created by analogy to a similar structure located around the rectum (mesorectum), whose radical excision-TME (total mesorectal excision) has led to a significant decrease in the loco-regional recurrence rate for carcinoma of the rectum. The name mesopancreas was introduced in 2007 [4].

The anatomical description is as follows: it is a borderless structure, extending from the posterior surface of the pancreas and the adjacent superior mesenteric vein through the space to the right and left of the superior mesenteric artery (SMA) down to the inferior vena cava, the aorto-caval groove, and the aorta. Histologically, a fatty tissue, nerve plexuses and ganglia, blood and lymphatic vessels, and lymph nodes can be found within it. Importantly, it has no fibrous capsule or fascia, making it invisible and very difficult to identify during surgery [5].

To this day, research continues to delineate its borders, and thus, there is no universal definition that is applicable in clinical practice [6].

Marek Olakowski

olakom@me.com

1 Department of Gastrointestinal Surgery, Medical University of Silesia, Katowice, Poland
Some propose to extend the name of this structure to the duodenal region and call it mesopancreatoduodenum rather than just mesopancreas. Their observations suggest that the duodenum-pancreas and SMA together form a complex structure both morphologically, developmentally, functionally, and pathologically [7].

Others, due to the difficulty in defining the anatomical borders of the mesopancreas, question the use of this term. They even propose to replace it with a new name after the performed procedure "en bloc proximal peri-mesenteric clearance" (PPMC). It consists of the removal of all lymph nodes along with the surrounding tissues around the proximal mesenteric vessels, especially the SMA [8].

There are also opinions that anatomically such a concept is a myth, because there was no envelope of fibrous sheath or fascia around these structures, similar to the mesorectum. The presence of vessels, nerves, and lymphatics within the retroperitoneal adipose tissue is not sufficient to justify the identification of these structures as a true "meso" since the two peritoneal leaves surrounding the vessels and linked with the parietal peritoneum are not present. Neither is there a "holy plane" of dissection, ensuring its complete and easy removal [9].

Just as there is controversy about the borders of the mesopancreas, there are also differences in opinion about which tissues within it are the most important.

Some consider it to be the ganglia and nerve plexuses extending between the appendix and superior mesenteric plexus (SMPlx) along the inferior pancreaticoduodenal artery (IPDA) and the body/tail and visceral plexus, as cancer cells spread via neural routes (perineural invasion) [10].

Others, based on anatomical studies, suggest that not only nerve plexuses but fibrous tissue is the basis of this structure. Therefore, they propose calling this plate-like structure the "pancreas-major arteries ligament" (P-A ligament), because it lies between the pancreas and major arteries (aorta, CeT, and SMA) [11]. 
Surgeons from Japan think that the mesopancreas is mainly nerve and fibrous tissue (NFT). They divide the NFT zone around the SMA into 4 areas of increased density "intensive NTFs area" and 3 areas of nerve plexus around this artery. In complete resection of all 4 fields of NFTs while preserving the nerve plexus around the SMA, they see a new variation of radical PD [12].

Still others pay attention to the lymphatic system and the flow of lymph therein, as the lymphatic pathways from the head of the pancreas are connected to the superior mesenteric artery via the inferior pancreaticoduodenal artery and the first jejunal artery [13].

Whether mesopancreas is the correct name is still unknown. Whether a better term is so-called mesopancreasmaybe. But leaving aside the name and the disputes, one cannot help, but notice a real progress of various surgical techniques aimed at a precise exploration of this space. Their primary goal is to apply for a tumor cell-free resection margin that provides the best outcome in pancreatic cancer. Thus, we currently have different approaches to the SMA and different scopes of excision of the surrounding tissues starting from "artery-first" [14] through "uncinate process first" [15], mesopancreas-first [16] to TRIANGLE operation [17].

Notwithstanding the anatomical correctness of the name mesopancreas, I believe that there is currently no better term that describes the image of this space and is understood by all specialists interested in pancreatic surgery.

It would be very useful and important to reach a worldwide consensus on the concept, landmarks, technique of mesopancreas excision, and evaluation of oncologic outcomes after this type of surgery [18].

Undoubtedly, improving our knowledge of the surgical anatomy of this region and technical improvement of mesopancreas excision along with standardization of pathologic examination are now crucial for enhancing pancreatic cancer outcomes [19].

Therefore, although for many people mesopancreas may be a mirage, for others it certainly remains a new, unknown land and its knowing may be beneficial in the future. Perhaps, it is time for an international panel of pancreatic surgeons, working in well-known centers, to review the literature on this topic and develop an easy to use definition of mesopancreas and propose an extent of its resection in pancreatic cancer assessed primarily for clinical impact.

\section{Declarations}

Ethics approval This article does not contain any studies with human participants or animals performed by the author.

Conflict of interest The author declares no competing interests.

\section{References}

1. Mizrahi JD, Surana R, Valle JW, Shroff RT (2002) Pancreatic cancer. Lancet 395:2008-2020. https://doi.org/10.1016/S01406736(20)30974-0

2. Strobel O, Neoptolemos J, Jäger D, Büchler MW (2019) Optimizing the outcomes of pancreatic cancer surgery. Nat Rev Clin Oncol 16:11-26. https://doi.org/10.1038/s41571-018-0112-1

3. Maeda S, Moore AM, Yohanathan L, Hata T, Truty MJ, Smoot RL, Cleary SP, Nagorney DM, Grotz TE, Park EJ, Girgis MD, Reber HA, Motoi F, Masuda T, Unno M, Kendrick ML, Donahue TR (2020) Impact of resection margin status on survival in pancreatic cancer patients after neoadjuvant treatment and pancreatoduodenectomy. Surgery 167:803-811. https://doi.org/ 10.1016/j.surg.2019.12.008

4. Gockel I, Domeyer M, Wolloscheck T, Konerding MA, Junginger T (2007) Resection of the mesopancreas (RMP): a new surgical classification of a known anatomical space. World $\mathrm{J}$ Surg Oncol 5:44. https://doi.org/10.1186/1477-7819-5-44

5. Mesopancreas PN (2015) A boundless structure, namely the rationale for dissection of the paraaortic area in pancreaticoduodenectomy for pancreatic head carcinoma. World J Gastroenterol 21:2865-2870. https://doi.org/10.3748/wjg.v21.i10.2865

6. Gao Y, Wang R, Lai Y, Xu Y, Lv W, Liu J, Fu Y, Duan W (2021) Morphological speculation of the MHPD and related clinical projections. Surg Radiol Anat. https://doi.org/10.1007/ s00276-021-02725-6

7. Yi S, Nagakawa Y, Ren K, Dai YD, Zhang M, Chen JF, Wang ZD, Miwa Y, Liu T, Lu XM (2020) The mesopancreas and pancreatic head plexus: morphological, developmental, and clinical perspectives. Surg Radiol Anat 42:1501-1508. https://doi.org/ 10.1007/s00276-020-02547-y

8. Kang MJ, Kim SW (2020) En bloc proximal peri-mesenteric clearance for pancreatic head cancer surgery. Ann Hepatobiliary Pancreat Surg 24:389-395. https://doi.org/10.14701/ahbps. 2020.24.4.389

9. Agrawal MK, Thakur DS, Somashekar U, Chandrakar SK, Sharma D (2010) Mesopancreas: myth or reality? JOP $11: 230-233$

10. Yi SQ, Miwa K, Ohta T, Kayahara M, Kitagawa H, Tanaka A, Shimokawa T, Akita K, Tanaka S (2003) Innervation of the pancreas from the perspective of perineural invasion of pancreatic cancer. Pancreas 27:225-229. https://doi.org/10.1097/ 00006676-200310000-00005

11. Muro S, Sirirat W, Ban D, Nagakawa Y, Akita K (2021) What comprises the plate-like structure between the pancreatic head and the celiac trunk and superior mesenteric artery? A proposal for the term "P-A ligament" based on anatomical findings. Anat Sci Int 96:370-377. https://doi.org/10.1007/s12565-020-00597-1

12. Nagakawa Y, Yi SQ, Takishita C, Sahara Y, Osakabe H, Kiya Y, Yamaguchi H, Miwa Y, Sato I, Tsuchida A (2020) Precise anatomical resection based on structures of nerve and fibrous tissue around the superior mesenteric artery for mesopancreas dissection in pancreaticoduodenectomy for pancreatic cancer. J Hepatobiliary Pancreat Sci 27:342-351. https://doi.org/10.1002/jhbp.725

13. Matsuki R, Sugiyama M, Kogure M, Yokoyama M, Nakazato T, Suzuki Y, Mori T, Abe N, Sakamoto Y (2021) Optimal lymphadenectomy of the mesopancreas based on fluorescence imaging during pancreaticoduodenectomy. J Gastrointest Surg 25:1241-1246. https://doi.org/10.1007/s11605-020-04619-1

14. Sanjay P, Takaori K, Govil S, Shrikhande SV, Windsor JA (2012) 'Artery-first' approaches to pancreatoduodenectomy. Br J Surg 99:1027-1035. https://doi.org/10.1002/bjs.8763

15. Hackert T, Werner J, Weitz J, Schmidt J, Büchler MW (2010) Uncinate process first-a novel approach for pancreatic head 
resection. Langenbecks Arch Surg 395:1161-1164. https://doi. org/10.1007/s00423-010-0663-9

16. Inoue $Y$, Saiura A, Yoshioka R, Ono Y, Takahashi M, Arita J, Takahashi Y, Koga R (2015) Pancreatoduodenectomy with systematic mesopancreas dissection using a supracolic anterior artery-first approach. Ann Surg 262:1092-1101. https://doi.org/ 10.1097/SLA.0000000000001065

17. Hackert T, Strobel O, Michalski CW, Mihaljevic AL, Mehrabi A, Müller-Stich B, Berchtold C, Ulrich A, Büchler MW (2017) The TRIANGLE operation - radical surgery after neoadjuvant treatment for advanced pancreatic cancer: a single arm observational study. HPB (Oxford) 19:1001-1007. https://doi.org/10.1016/j.hpb. 2017.07.007

18. Ramia JM, De-la-Plaza R, Manuel-Vazquez A, Lopez-Marcano A, Morales R (2018) Systematic review of the mesopancreas: concept and clinical implications. Clin Transl Oncol 20:13851391. https://doi.org/10.1007/s12094-018-1869-5

19. Fernandes ESM, Strobel O, Girão C, Moraes-Junior JMA, Torres OJM (2021) What do surgeons need to know about the mesopancreas. Langenbecks Arch Surg. https://doi.org/10.1007/ s00423-021-02211-y

Publisher's note Springer Nature remains neutral with regard to jurisdictional claims in published maps and institutional affiliations. 